\title{
On two remarkable species of Azeliinae (Diptera: Muscidae), previously unknown from the Balkans, but collected from Bulgaria already in the $20^{\text {th }}$ century
}

\author{
Eberhard Zielke
}

Institute of Biodiversity and Ecosystem Research, Bulgarian Academy of Sciences, 1 Tsar Osvoboditel Blvd, 1000 Sofia, Bulgaria, eo.zielke@abv.bg

\begin{abstract}
Achanthiptera rohrelliformis (Robineau-Desvoidy, 1830) and Hydrotaea aenescens (Wiedemann, 1830), two species of the subfamily Azeliinae (Muscidae), are recorded for the first time from Bulgaria, although they have been already collected around 1908 and 1973, respectively. Due to the fact that the specimen of A. rohrelliformis has not been determined earlier and that males and females of $H$. aenescens have been erroneously assigned to Ophyra leucostoma (Wiedemann, 1817), the findings of the two species, new to the muscid fauna from Bulgaria and the Balkan Peninsula, are only reported now.
\end{abstract}

Keywords: Azeliinae, Achanthiptera rohrelliformis, Hydrotaea aenescens, new records, Bulgaria, Balkan countries

\section{Introduction}

The first and only comprehensive compilation of the muscid fauna from Bulgaria has been presented by Lavčiev (2003), based on earlier published reports and his own observations on the Muscidae from Bulgaria. The catalogue contains 220 species assigned to 35 genera and five subfamilies of the family. Since then some groups of Muscidae have been reviewed and the validity of some species and the assignments to genera or even subfamilies have been changed, e. g. see the Manual of Central European Muscidae (Gregor et al., 2016). In addition, 22 muscid species and one genus have been recorded as new from Bulgaria (Zielke, 2016a, 2016b, 2017, in press). Apart from a recently captured Limnophora species (Zielke, 2017) all other newly reported species belong to the subfamilies Mydaeinae and Phaoniinae. They were collected in the last century and stored in the muscid collection of the Institute of Biodiversity and Ecosystem Research (IBER), Sofia, Bulgaria. In addition to the recently reported records of Mydaeinae and Phaoniinae, specimens of two remarkable species, namely
Achanthiptera rohrelliformis (Robineau-Desvoidy, 1830) and Hydrotaea aenescens (Wiedemann, 1830), were discovered in the collection of IBER. Both species, which belong to the muscid subfamily Azeliinae and which have not been reported yet from Bulgaria and the Balkan Peninsula, are introduced below.

\section{Material and methods}

Keys to the Muscidae of the Palaearctic Region (Hennig, 1964) and to the Muscidae of Central Europe (Gregor et al., 2016) were used for identification. External morphological features were examined using a ZEISS Stemi 2000-C stereomicroscope, for illustrations an AxioCam ERc5s camera and for further processing Helicon Focus 6 and Adobe Photoshop CS2 were applied.

\section{- Achanthiptera rohrelliformis}

(Robineau-Desvoidy, 1830)

This species is the only representative of the genus Achanthiptera Rondani, 1856. Due to the presence 


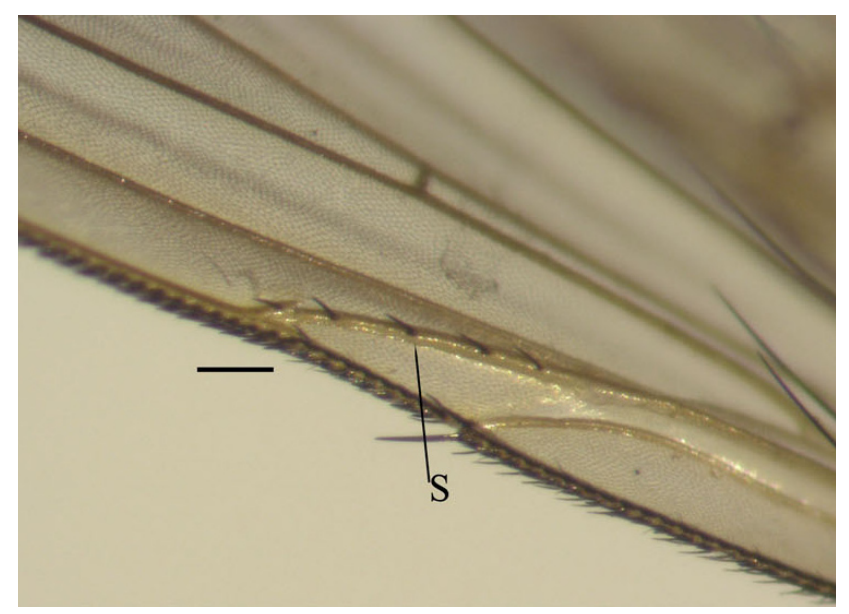

Fig. 1. Achanthiptera rohrelliformis $\hat{O}$, apical part of wing vein $R_{1}$ with setae $(S)$ on the dorsal surface (bar $=0,2 \mathrm{~mm}$ ).

of spiracles on the sixth abdominal segment of the female, Hennig (1965) even assigned the genus to an own subfamily, Achanthipterinae. Kutty el al. (2014), however, could show that the postabdominal spiracles of the female were a mistaken observation. This finding together with results of molecular studies conducted by the same authors led to the decision to position the genus close to Potamia Robineau-Desvoidy, 1830 in the subfamily Azeliinae, as suggested earlier by Skidmore (1985), based on larval morphology and the biology of Achanthiptera.

Males and females of $A$. rohrelliformis are midsized flies with body length of 6 to $9 \mathrm{~mm}$. They are easily differentiated from other muscid species by the typical combination of taxonomic characters: bare anepimeron, predominantly yellow-coloured body and in particular distinct setulae dorsally on the surface of the apical third of wing-vein $\mathrm{R}_{1}$ (Fig. 1). Generally, adults of A. rohrelliformis are short-lived and are usually observed in the surroundings of nests of wasps or hornets in which the larvae develop. The eggs are oviposited in the nests from June onwards and contain already well developed larvae which hatch almost immediately after the eggs have been positioned by the female (Vos de Wilde, 1935 in Skidmore, 1985). The larvae are trimorphic and facultative carnivores, feeding on organic debris produced in the nests, including dead wasps and their larvae, as well as on other soft-bodied larvae developing in the same habitat. The maggots stay in the nests of the Hymenoptera throughout winter and pupate in the ground in spring. The adults emerge in summer from June till early Au-

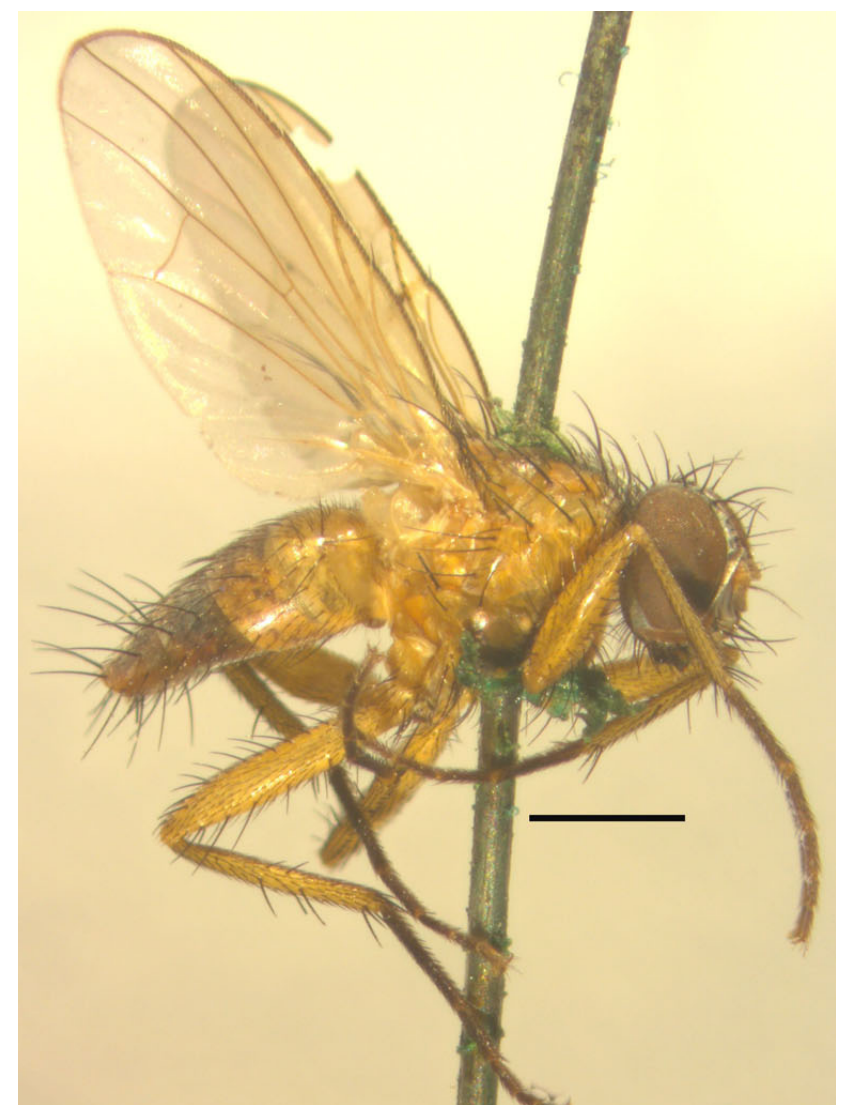

Fig. 2. Achanthiptera rohrelliformis ડ̄, collected in Sofia by Nedelkov in August, presumably 1907 or 1908 (bar = $1 \mathrm{~mm})$.

gust. Probably due to the specific life cycle, adults of A. rohrelliformis are not very commonly found.

Little is known on the distribution of $A$. rohrelliformis in the Asian part of the Palaeartic Region. Skidmore (1985) indicated the Western Palaearctic Region with Tajikistan to the East as distribution area of the species whereas Sorokina \& Pont (2010) included also Siberia and China in the species distribution area. According the website of Fauna Europaea (Pont, 2013) the species is known from the majority of the European countries, but hitherto it has not been recorded from the most south-eastern part of Europe, the countries which belong to the Balkan Peninsula sensu strictu, i.e. apart from the small Balkan part of Romania all countries from Greece to Slovenia and from Bulgaria and Serbia to the eastern coast of the Adriatic Sea.

Recently, however, a fly (Fig. 2) was detected among the unidentified muscid material of IBER, which proved to be a male of $A$. rohrelliformis. Its 
rather old and slightly yellowed locality label bears the handwritten information "Sofia, VIII" and the printed name "col. Nedelkoff". The year of the capturing is not mentioned. However, other Muscidae, which have been collected by Nedelkoff in Sofia and its vicinity and which are located in the collection of IBER with similar locality labels, originate all from collecting activities of the years 1907 and 1908. Therefore, it can be assumed with high probability, that this fly has been captured in this period as well. Thus A. rohrelliformis is since long a member of the Bulgarian muscid fauna but has not been recognized as such. Neither did Nedelkoff mention the species in his publications on the Bulgarian Muscidae (1909, 1910, 1912) nor did Lavčiev (2003) include A. rohrelliformis in the overview of the Bulgarian muscid fauna. This is now the first record of the genus Achanthiptera and its only species $A$. rohrelliformis from Bulgaria and, consequently from the Balkan Peninsula, although the record is based on a fly collected about 110 years ago. The specimen has been in the IBER collection as a loan from the National Museum of Natural History, Sofia for some time and will be returned to the collection of the museum.

\section{- Hydrotaea aenescens (Wiedemann, 1830)}

In general, the adults of all Hydrotaea-species Robineau-Desvoidy, 1830 known from the Palaearctic Region are marked with dark palpi and antennae. $H y$ drotaea aenescens, previously known as Ophyra aenescens (Wiedemann, 1830), is the only Palaearctic species of which males and females are characterised by yellow to ochre palpi and a yellowish base of the antennae. Therefore, its adults are easily distinguished from other species of the genus. The males and females of $H$. aenescens are of about 5 to $6 \mathrm{~mm}$ in body length and have dark, metallic shining body, similarly to all those Hydrotaea-species, which have been previously placed in the genus Ophyra Robineau-Desvoidy, 1830. In addition, the fore femora of males of this specific group are not modified at distal tip by teeth, tubercles and/or ridges, as it is observed for the males of most of the "classical" Hydrotaea species.

$H$. aenescens is also called the "American black dump fly" (e.g. Pont et. al., 2007) and adults are most commonly found on garbage, vertebrate carrion and around urban refuse disposal sites. The larvae are trimorphic and develop in organic waste and cadavers. They are semi-carnivorous, i.e. they also prey on other muscid larvae sharing their habitat. Their develop- ment is positively influenced when they can feed on maggots of the house fly Musca domestica Linnaeus, 1758 (Müller, 1982). The duration of the complete life cycle of $H$. aenescens depends on temperature, humidity and food media and at optimum conditions it lasts eight days (Schumann, 1982). All this is also the reason why $H$. aenescens has repeatedly been discussed as potential control of the larvae of the house fly (e.g. Skidmore, 1985).

The American dump fly is widespread and abundant in the warmer areas of the Neotropical and Nearctic Regions. According to Pont et al. (2007), the species has already been mentioned from Europe by Stein in Becker et al. (1907) and some other authors (e. g. Séguy, 1937, Oliveira, 1941) also did not exclude a possible occurrence of the species in Europe. But it seems that the distribution of $H$. aenescens in Europe started only in the early 1960s. Since then, the species spread widely and rapidly in Europe. Pont et al. (2007) provided a compilation of the first records of the species from the various countries and Vikhrev (2008) published a map showing (apart from few inconsistencies) the records of $H$. aenescens from the western part of the Palaearctic Region based on the compilation of Pont. The author also reported Russia as a new record of the species, which had been found in the South and in the far North of European Russia. The information on the distribution of $H$. aenescens available in Fauna Europaea (version 2017.06) is only partly in line with the update provided by Pont et al. (2007). Countries such as the Netherlands, Britain and Ireland are missing, although data on the occurrence of the species in these countries have been published already in 2007. And neither the new records from Russia published by Vikhrev (2008) are taken in account by the latest version of the website, nor is considered the new record of $H$. aenescens from Poland from 2007 (Draber-Monko, 2007). All these records of $H$. aenescens document that the species occurred practically in the mainland of all Western European countries, apart from Belgium and Luxembourg. But there are also two large areas where $H$. aenescens has not been registered yet, namely an Eastern located belt, starting with Ukraine and Moldavia in the South and extending over Belarus and the Baltic states to Finland and Sweden in the North, and (apart from Romania) in the Balkan countries and the European part of Turkey in South East Europe.

However, when reviewing Hydrotaea specimens of the entomological collection of IBER which had 


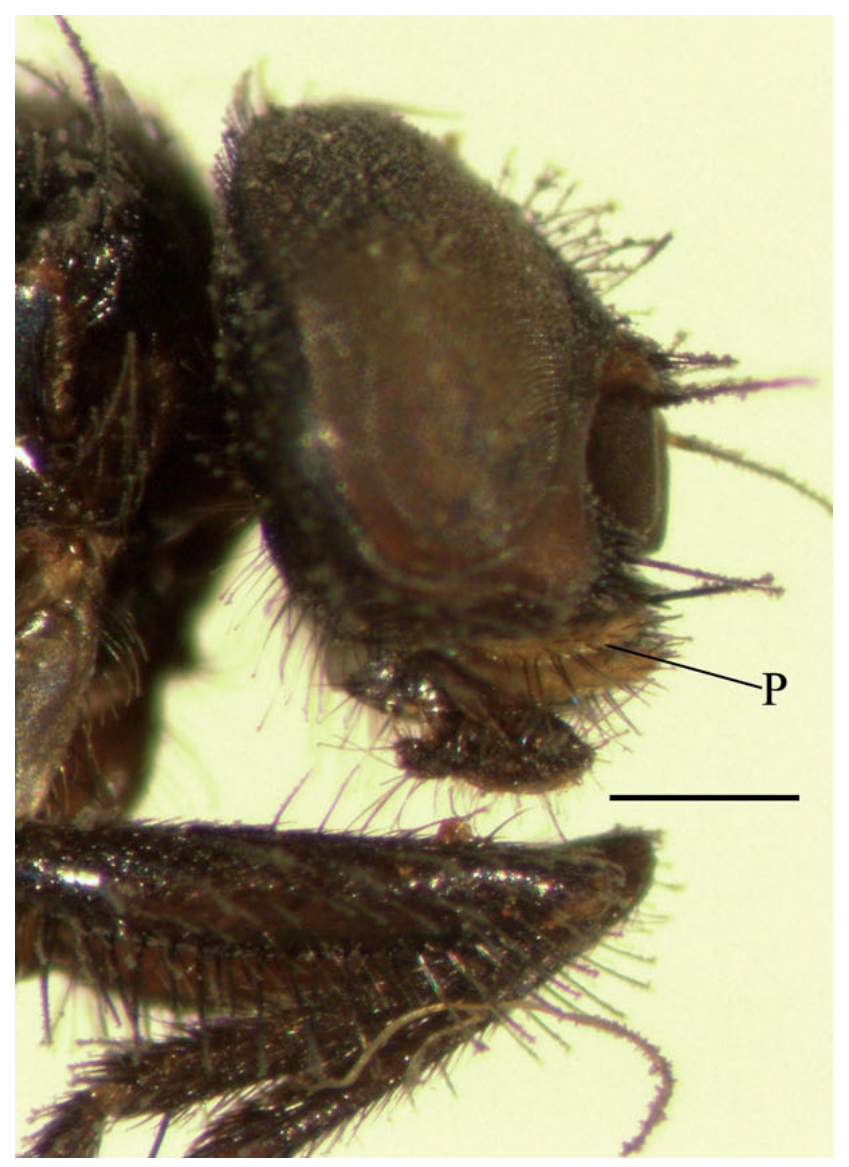

Fig. 3. Head of one of the males of Hydrotaea aenescens of the group labelled as "Ophyra leucostoma (Wiedemann)" with yellow palpi (P), collected in 1973 in Bulgaria (bar = $0,5 \mathrm{~mm})$.

been determined at earlier times but which were only provisionally labelled, a group of seven males and eight females originating from Bulgaria was found and studied. The group was collectively marked with a larger piece of paper with the following information, handwritten partly with Cyrillic letters: "O Ophyra leucostoma, Svoge, 12.7.1973, with coloured (?) $t_{3}$, railway station, Drugarska sreshta". Identifier and date of identification were not named. Ophyra leucostoma (Wiedemann, 1817) is a synonym of Hydrotaea ignava (Harris, 1780) and four of the females indeed belonged to this species. All seven males and the other four females were characterised by yellow base of antennae and yellow palpi and unambiguously proved to be $H$. aenescens. $H$. aenescens had been collected already in Bulgaria as early as July 1973, the same year in which the species was observed also in France for the first time. According to Pont et al. (2007), the spe- cies occurred earlier than 1973 only in Austria, Italy, Spain, Germany and Denmark; in all other European countries the fly was registered in 1975 and the following years. Due to an error of assignment, however, the species has not been recorded from Bulgaria and the first report on the early occurrence of $H$. aenescens from Bulgaria and the Balkan Peninsula is made now, about 45 years late.

\section{Acknowledgements}

I am very grateful to Toshko Ljubomirov Ph.D., Associate Professor and curator of the Zoological Collection of the Institute for Biodiversity and Ecosystem Research, for supporting my research on Muscidae by giving me generous access to the collection of Diptera and for providing all facilities needed for the examination of the material. In particular I also have to thank him for the translation of the locality label. I would like to thank also the reviewers for helpful comments and corrections for the improvement of this paper.

\section{References}

Becker T., Bezzi M., Kertész K., Stein P. (eds) 1907 Cyclorrhapha Achiza. Cyclorrhapha Schiziphora: Schizometopa. Katalog der paläarktischen Dipteren 3. Budapest, $828 \mathrm{pp}$.

Draber-Mońko A. 2007 Muscidae. In: Bogdanowicz W., Chudzicka E., Pilipiuk I., Skibińska E. (eds) Fauna of Poland, characteristics and checklist of species 1. Muzeum i Instytut Zoologii PAN, Warzawa, 142-144, 226-229.

Gregor F., Rozkošny R., Barták M., Vaňhara J. 2016 Manual of Central European Muscidae (Diptera). Zoologica 162: 1-220.

Hennig W. 1964 Muscidae. In: Lindner, E. (ed) Die Fliegen der palaearktischen Region. E. Schweizerbart'sche Verlagsbuchhandlung, Stuttgart 63 b: $1-1110$.

Hennig W. 1965 Vorarbeiten zu einem phylogenetischen System der Musciden (Diptera: Cyclorrhapha). Stuttgarter Beiträge zur Naturkunde 141: $1-100$.

Kutty S.N., Pont A.C., Meier R., Pape T. 2014 Complete tribal sampling reveals basal split in Muscidae (Diptera), confirms saprophagy as ancestral feeding mode, and reveals an evolutionary corre- 
lation between instar numbers and carnivory. Molecular Phylogenetics and Evolution 78: 349-364.

Lavčiev V. 2003 Catalogus faunae bulgaricae 5. Diptera: Fannidae, Muscidae, Stomoxydidae. Pensoft, Sofia, $77 \mathrm{pp}$.

Müller P. 1982 Zur Bedeutung des Musca domesticaAntagonisten Ophyra aenescens (Diptera, Muscidae) III. Laborversuche zur Wechselwirkung zwischen den Larven von Musca domestica und O. aenescens. Angewandte Parasitologie 23: 143154.

Nedelkov N. 1909 Nashata entomologichna fauna. Arhiv na Ministerstvoto na narodnoto prosveshtenie 1 (3): 83-135. (In Bulgarian).

Nedelkov N. 1910 Beitrag zu Dipteren Bulgariens. Internationale Entomologische Zeitschrift 4 (7): 36-37.

Nedelkov N. 1912 Shesti prinos kam entomologichnata fauna na Balgaria. Spisanie na Balgarskata akademiya na naukite 2: 177-218. (In Bulgarian)

Oliveira S.J. de 1941 Sôbre Ophyra aenescens (Wiedemann, 1830) (Diptera: Anthomyiidae). Archivos de Zoologia São Paulo 2: 341-355.

Pont A.C. 2013 Fauna Europaea: Muscidae. In: Pape T., Beuk P. (eds) Fauna Europaea: Diptera Brachycera. Fauna Europaea, version 2017.06, https:// fauna-eu.org (last access at 28.07.2018).

Pont A.C., Lole M.J., Leblanc H.N., Cole J.H. 2007 The American black dump fly Hydrotaea aenescens (Wiedemann, 1830) (Diptera, Muscidae) in Britain and Ireland. Dipterists Digest 14: 23-29.

Schumann H. 1982 Zur Bedeutung des Musca domestica-Antagonisten Ophyra aenescens (Diptera: Muscidae). II. Morphologie der Entwicklungsstadien. Angewandte Parasitologie 23: 86-92.
Séguy E. 1937 Diptera Fam. Muscidae. In: Wytsman P. (ed) Genera Insectorum 205: 1-605.

Skidmore P. 1985 The biology of the Muscidae of the World. Series Entomologica 29: 1-550.

Sorokina V.S., Pont C.A. 2010 An annotated catalogue of the Muscidae (Diptera) of Siberia. Zootaxa 2597: 1-87.

Vikhrev N. 2008 New data on the distribution and biology of the invasive species Hydrotaea aenescens (Wiedemann, 1830) (Diptera, Muscidae). ZooKeys 4: 47-53.

Vos de Wilde B. 1935 Contribution à l'étude des Diptères cyclorrhaphes, plus spécialement des larves d'Anthomyides. Amsterdam. Dissertation, 125 pp.

Zielke E. 2016a Update of distribution records of Phaonia Robineau-Desvoidy (Diptera: Muscidae) from Bulgaria with the description of a new species. Journal of Entomology and Zoology Studies 4 (4): 626-632.

Zielke E. 2016b Update of distribution records of Mydaeinae (Diptera: Muscidae) from Bulgaria. Journal of Entomology and Zoology Studies 4 (6): 310-315.

Zielke E. 2017 Description of a new Limnophora species from Bulgaria (Diptera: Muscidae). Contributions to Entomology 67 (2): 319-323.

Zielke E. In press Update of distribution records of Helina R.-D. and other genera of the subfamily of Phaoniinae (Diptera: Muscidae) from Bulgaria. Acta Musei Moraviae, Scientiae biologicae (Brno) 103. 